\title{
Exploring Career and Technical Education as an Educational Solution to At-Risk Students and School Dropouts at the Centre de Formation Professionnelle de Dogbo (Benin)
}

\author{
Jean-Marc Gnonlonfoun
}

GRI-DiGeST/Ecole Normale Supérieure, Lokossa, Benin

DOI: $10.36348 / \mathrm{sijl1.2020.v03i04.002}$

| Received: 27.03.2020 | Accepted: 04.04.2020 | Published: 09.04.2020

*Corresponding author: Jean-Marc Gnonlonfoun

\section{Abstract}

In educational administration, at-risk students as well as dropouts have always been a serious subject of reflection. In the quest of solutions to address the educational needs of these students who, for wide range of motives, could no more fit in the traditional educational system, various approaches have been sought. One of these is alternative education as delivered in specific centres such as the Centre de Formation Professionnelle de Dogbo. This study, a seven months research action study, assumes that the trade-oriented education programs of the centre are more effective in re-engaging academic understanding of mathematics (algebra) to at-risk students and school dropouts enrolled. To verify this hypothesis, a pre- test versus post-test comparison was made from tests administered to a single class of thirty-four students after a Maths (Algebra) class was co-taught with a Career and Technical Education (CTE)/Masonry teacher twice a week from January 2018 to May 2018. The results evidenced that CTE motivates at-risk students to have higher levels of academic engagement and aspiration to stay in school. Furthermore, the students demonstrated competence of the work expectations and the desire to further their learning process.

Keywords: At-risk and dropout students.

Copyright @ 2020: This is an open-access article distributed under the terms of the Creative Commons Attribution license which permits unrestricted use, distribution, and reproduction in any medium for non-commercial use (NonCommercial, or CC-BY-NC) provided the original author and source are credited.

\section{Problem AND PURPOSE}

In Benin, traditional education has yet to commit to the task of providing success for all students. Indeed, a school's "miscreants" are dealt with on individual basis. This means that student suspensions and expulsions are generally handled individually. In the race to complete the administrative procedures and facilitate the process, school officials rarely have time to examine the total effect of the exclusion process.

Once expelled, parents start looking for other solutions to help their children: private schools, learning centres, etc. Many children and their families engage in a struggle with schooling. The struggles all bear the unique stamp of the individuals that experienced expulsion, suspension, or other forms of rejection. Nevertheless, the individuals are bonded together in their alienation and elimination from further participation in the schooling process. These students sometimes evoke educators' tears of frustration, but more often, their behavior evokes a rage that leaves the student ostracized from the school. Their misbehavior, be it prankish or criminal challenge teachers to question their professional skills and their ethics.

One of the approaches found by the government is the creation of the Centres de Formation Professionnelle (CFP) also called Career and Technical Education Centres (CTE). Indeed, these centres are official government centres that are opened with one purpose: providing professional alternative education that is career oriented to at-risk high school students and other dropout students. The main issue raised is how do such such centres carry out the job of reaching the student who has become so accustomed to academic failure?

A temptative response is that pedagogical approaches used in the centres respond to the educational needs of disaffected youth. In the CFP of Dogbo, it is noted that instructional strategies such as conceptualized learning and experiential learning are used to engage and fulfill the academic needs of the disaffected student, who is both over aged and under credited. Both learning models have proven to be effective especially with over-aged students that require 
instruction to be relevant to their lives and "targeted towards more intense involvement in a particular field" [1]. The fields investigated in the said centre are masonry.

\section{LITERATURE}

From the time of Plato up to now, the only constant actor in the educational process is the learner. It was in the era of John Dewey, the educational theorist, that the public heard a dissident voice regarding revision of education. Dewey recalled people that the key objective of education was to foster the development of free and independent intellectuals who live in a democratic society.

In the last decades, there has been a growing movement away from the traditonal way of educating youth. It has become compulsory to provide options for students that go beyond the traditonal academic setting. Currently, there are 11 CFPs throughout the country (Annuaire Statistique du MESTFP, 2000-01) [2]. Each of these centres works in its own unique way to meet the needs of the students who have found their way out of the traditional program and into the alternative school.

Furthermore, in the words of Aron [3], these centres have proven beneficial for at-risk students in that they provide viable opportunities with academic instruction, instructional staff, class size and community relationships. The CFPs can be likened to the Twilight Academy established in the United States of America for nearly the same purposes. Angelo \& Zemanick [4] give a descriptive overview of the first incoming class and a description often given to students who are admitted to alternative schools:

The Twilight Academy came from a need to reach a growing number of students who for one reason or another were not successful in a traditional classroom or in a traditional school. An increasing number of students who ultimately enrolled in this school had been falling behind, failing multiple grades, becoming disruptive in the classroom when they actually showed up for school, and dropping out. These students were not experiencing success in the classroom because they were square pegs being forced into a round hole of education that did not work for them. The Twilight Academy [provides] a different atmosphere, more individualized attention, and a focus on skills that would enable these students to be successful in the world. (p.212)

In the end, the first graduating class of the Twilight Academy successfully graduated eleven out of the twelve students their first year. Their success was due to a variety of factors but most importantly was because of the curriculum link of a work component to the academic program which made the coursework more real and purposeful for the students. Furthermore, this link provided options after graduation, thus giving the students of the Twilight's alternative program life and hope beyond the classroom.

As indicated by Bennet [5], developing and identifying an occupational [or alternative] during school pathways enables [at-risk] students to develop a motivating self image or vision of the future person they wish to become.

The benefits of alternative education for at-risk youth has inspired much literature in support of the academic and life long rewards to the disaffected learner "to reconnect to education and/or identify ways they can be productive and creative if given the opportunity" enables their identity as a productive student who can contribute to the school and community [6]. Such literature has dealt with the pros of this type of education for at-risk students [7] in terms of intrinsic motivation, positive rapports between school authorities, teachers and students, improved interpersonal relationship skills, personal development, immediate focus, numerous opportunities for at-risk students to learn and grow, the healing and recovery from abuse and self-defeating behavior through a a strong and supportive atmosphere that acknowledges the challenges of personal growth and the joy that can come from success.

The limits are also addressed and include the fact that for some students, school and course names are a constant reminder of their educational shortcomings, failure and overall rejection $[8,9,3]$, the necessity of being able to clearly feel and see the products and outcomes of their efforts, an interconnection between education and future success in the areas of work, family, and community, assessment to demonstrate competence and to further the instructional process. This last point indicates the necessity of avoiding traditional tests as a method of evaluating learning in alternative education settings.

\section{METHODOLOGY OVERVIEW}

To carry out this study, permission was obtained from the CFP Director (through personal contact) to consult with two teachers and thirty-four students. This would enable to observe the effectiveness of the instructional strategies that employ Experiential and Contextualized learning, in a co-taught Mathematics (Algebra)/CTE class. As such, the sample of this study consists of 2 teachers and 34 students from one final a Masonry class of the CFP Dogbo. The 34 students comprise $65 \%$ or 22 students being boys and $35 \%$ or 12 students are girls. All students are formers dropouts registered in the CFP Dogbo for the school year 2017-2018. 
Likert scale surveys designed and administered to 2 teachers and 34 students. The teachers' surveys were to build background information and get an understanding behind the operation of a co-taught classroom, that involved students who required more individualized attention and focus on their academic shortcomings. Two surveys (one pretest survey and one posttest survey) were administered to the 34 students. Identical questions were asked on both surveys with the pretest survey used to measure the correlation of the student's confidence in their ability to approach math problems and the scores they achieved on 2 pretests. The posttest survey was used to measure the correlation of the student's content mastery of Integrated Algebra when co-taught with the Carpentry teacher and the scores they achieved on 2 posttests. Confidentiality was assured by changing participants' names.

\section{Experimental Design}

This action research aimed to evaluate the effectiveness of CTE as an educational solution to AtRisk Students at the Centre de Formation Professionnelle of Dogbo. Such a CTE facilitates two instructional strategies (1) Conceptualized Learning and (2) Experiential Learning to engage academic understanding of mathematics (Algebra) in the selected class. Hence, the pre-experimental design comprised a single class. This single class was pretested $(\mathrm{O})$, exposed to a treatment $(\mathrm{X})$, and posttested $(\mathrm{O})$. The symbolic design is as follows: OXO.

Threats to internal validity (such as history, maturation, testing, instrumentation, differential selection, mortality and selection-maturation interference) and external validity (pretest treatment, selection-treatment interference, experimenter effect and participants effects) are aspects to be taken into account so as to limit the generalizability of the study since they may have affected the performance and responses of the participants.

\section{Research Procedure}

Two major phases were observed in carrying out this research. The first phase included library research to complete the review of relevant literature that would frame the study. Upon completion of the first, the second phase was launched. It evolves around field study with weekly visits to the CFP Dogbo. The student population is made of youth who have recovered from drug addiction and/ or have dropped out of the traditional school setting for at least one year. Consequently, the school consists of at-risk youth that are in need of an alternative program to be affectively re-engaged in an academic setting and given a fresh start that results in job training, a qualification certificate through the instruction of Masonry.

Fig-1: Detailed timeline

\begin{tabular}{|l|l|}
\hline ACTIVITY & DURATION \\
\hline Literature review and Permission Request & $1-15$ November 2017 \\
\hline Meeting with Students for Explanation of Research and general agreement from students & 16 November 2017 \\
\hline $\begin{array}{l}\text { Questionnaires Distributed to and collected from the two teachers involved (Masonry } \\
\text { and Maths (Algebra) }\end{array}$ & $\begin{array}{l}17 \text { November }-15 \\
\text { December } 2017\end{array}$ \\
\hline Administration of pretest survey to all 34 students. & -21 December 2017 \\
\hline First blended class observation & -27 December 2017 \\
\hline Pretest $n^{\circ} 1$ administered to 34 students & 12 January 2018 \\
\hline Pretest $n^{\circ} 2$ administered to 34 students & 23 February 2018 \\
\hline Posttest $n^{\circ} 1$ administered to 34 students & 23 March 2018 \\
\hline Posttest $n^{\circ} 2$ administered to 34 students & 20 April 2018 \\
\hline Posttest Survey $n^{\circ} 2$ administered and collected from 34 students & 25 May 2018 \\
\hline The mathematics teacher handed over all grades of the assessment tests. & 28 May 2018 \\
\hline
\end{tabular}

\section{FINDINGS}

\section{Content Mastery}

The following figure illustrates the math content mastery of the 34 student participants. Furthermore, the chart displays 2 pretest scores and 2 posttest scores with the accompanying averages for the analysis. The pretest scores were generated prior to the CTE intervention. The posttest scores were generated after the administration of the CTE intervention. Through further analysis, 94\% of students showed an increase in math scores following CTE intervention. The gradual progression could be deemed as a threat to validity as the students were aggressively assessed daily with quizzes, weekly with unit tests and monthly with mock exams. 
Fig-2: Content mastery by student participants [10]

\begin{tabular}{|c|c|c|c|c|c|}
\hline & \multicolumn{2}{|c|}{ Content Mastery } & \multicolumn{2}{|l|}{ Content Mastery } & \multirow{3}{*}{$\begin{array}{l}\text { Percentage Change } \\
\text { Pretest vs Posttest Math }\end{array}$} \\
\hline & Pretest \#1 & Pretest \#2 & Posttest \#1 & Posttest \#2 & \\
\hline Student Pairs & Math only & Math only & Math with CTE & Math with CTE & \\
\hline 1 & $64 \%$ & $74 \%$ & $71 \%$ & $82 \%$ & $11 \%$ \\
\hline 2 & $79 \%$ & $79 \%$ & $81 \%$ & $88 \%$ & $11 \%$ \\
\hline 3 & $50 \%$ & $61 \%$ & $63 \%$ & $67 \%$ & $10 \%$ \\
\hline 4 & $62 \%$ & $62 \%$ & $71 \%$ & $74 \%$ & $19 \%$ \\
\hline 5 & $48 \%$ & $65 \%$ & $67 \%$ & $75 \%$ & $15 \%$ \\
\hline 6 & $75 \%$ & $77 \%$ & $85 \%$ & $80 \%$ & $4 \%$ \\
\hline 7 & $71 \%$ & $76 \%$ & $84 \%$ & $89 \%$ & $17 \%$ \\
\hline 8 & $74 \%$ & $74 \%$ & $78 \%$ & $79 \%$ & $7 \%$ \\
\hline 9 & $59 \%$ & $66 \%$ & $76 \%$ & $78 \%$ & $18 \%$ \\
\hline 10 & $83 \%$ & $85 \%$ & $88 \%$ & $90 \%$ & $6 \%$ \\
\hline 11 & $67 \%$ & $72 \%$ & $76 \%$ & $80 \%$ & $12 \%$ \\
\hline 12 & $43 \%$ & $50 \%$ & $51 \%$ & $53 \%$ & $6 \%$ \\
\hline 13 & $21 \%$ & $25 \%$ & $23 \%$ & $27 \%$ & $8 \%$ \\
\hline 14 & $56 \%$ & $60 \%$ & $67 \%$ & $74 \%$ & $23 \%$ \\
\hline 15 & $78 \%$ & $84 \%$ & $76 \%$ & $77 \%$ & $-8 \%$ \\
\hline 16 & $71 \%$ & $80 \%$ & $84 \%$ & $88 \%$ & $10 \%$ \\
\hline 17 & $66 \%$ & $72 \%$ & $79 \%$ & $82 \%$ & $14 \%$ \\
\hline Averages & $63 \%$ & $68 \%$ & $72 \%$ & $75 \%$ & $94 \%$ \\
\hline
\end{tabular}

\section{Pre-Experimental Design}

The one group pretest and posttest scores graph presented on the following page demonstrates and lists the gradual progression and improvement of math scores for the students participants $(n=34)$.

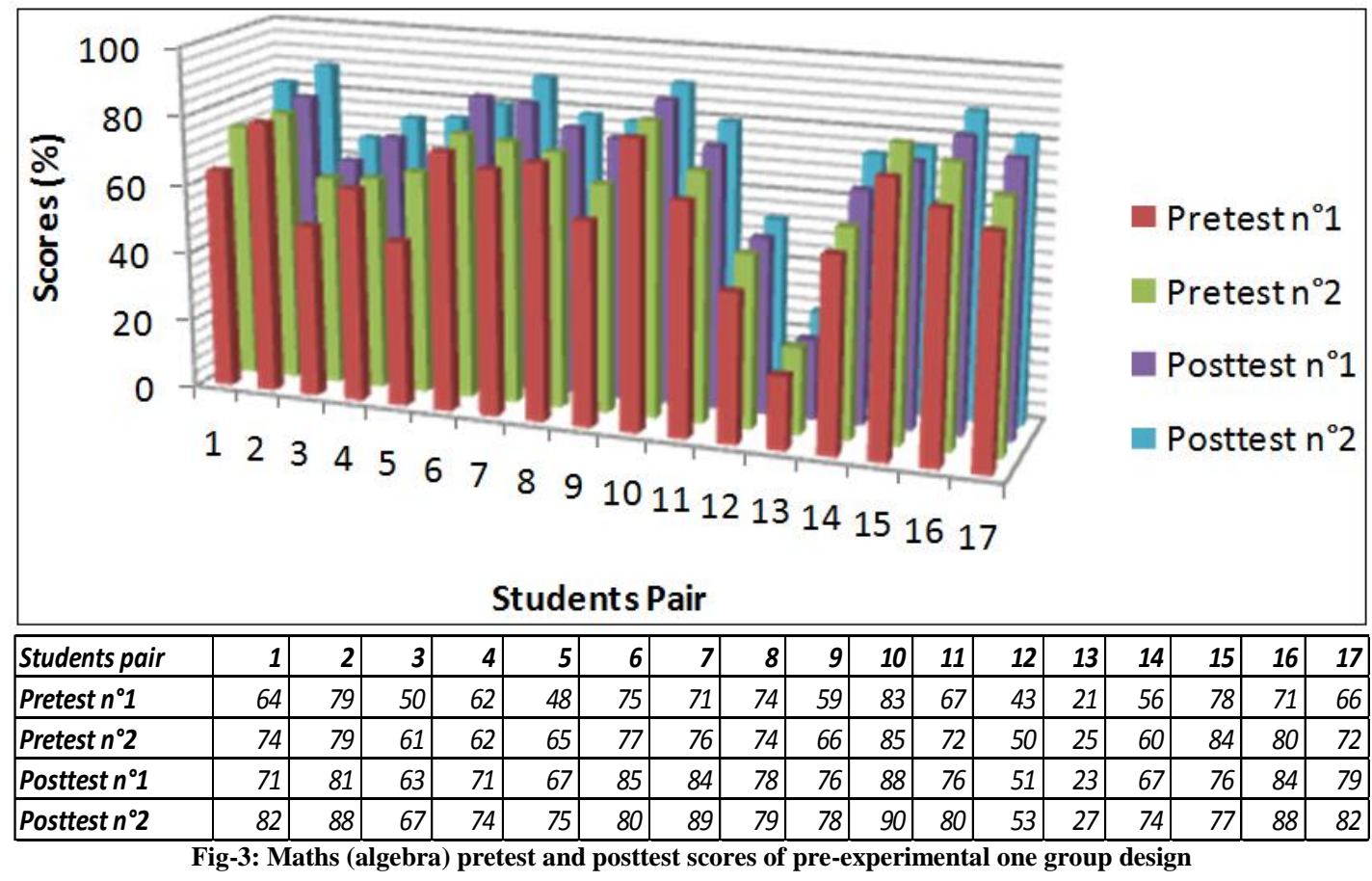

\section{Measures of Central Tendency}

The figure on the next page is an illustration of measures of central tendency to include the range of both the 2 pretests and the 2 posttests. The mean, median and mode estimates show a gradual progression of the test scores. The overall class averages from Pretest \#1 to Pretest \#2 illustrate the effectiveness of the intervention. 


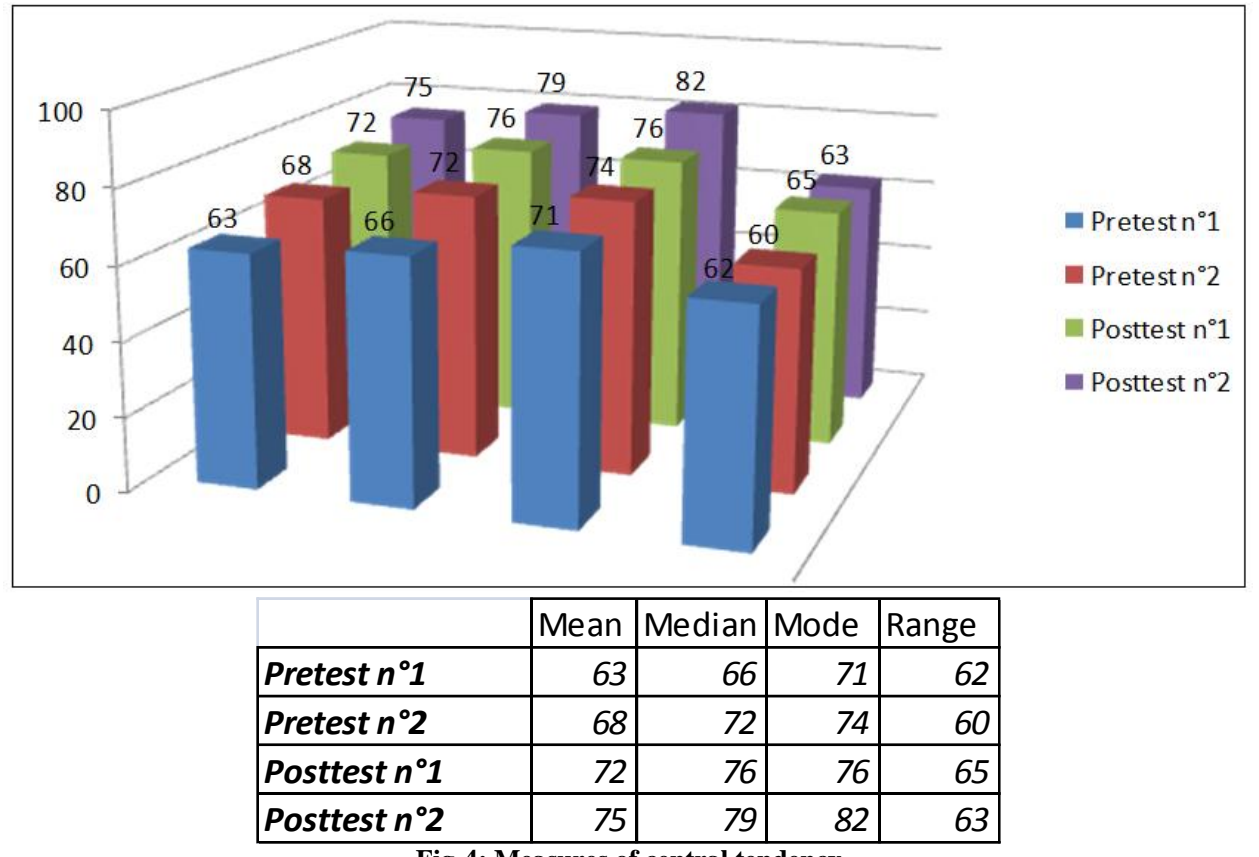

\section{Pretest Correlation $\mathbf{n}^{\circ} 1$}

The datum collected and presented below is an extract from the Student survey. It concerns specifically statement $\mathrm{n}^{\circ} 7$ which goes as follows:

\section{Statement 7: Solving math problems often makes me nervous and upset.}

Strongly Agree

(1)
Agree

(2)
Disagree

(3)

\section{Strongly Disagree}

(4)

The results from students are presented in the figure below:

Fig-5: Participants answers to statement $\mathrm{n}^{\circ} 7$

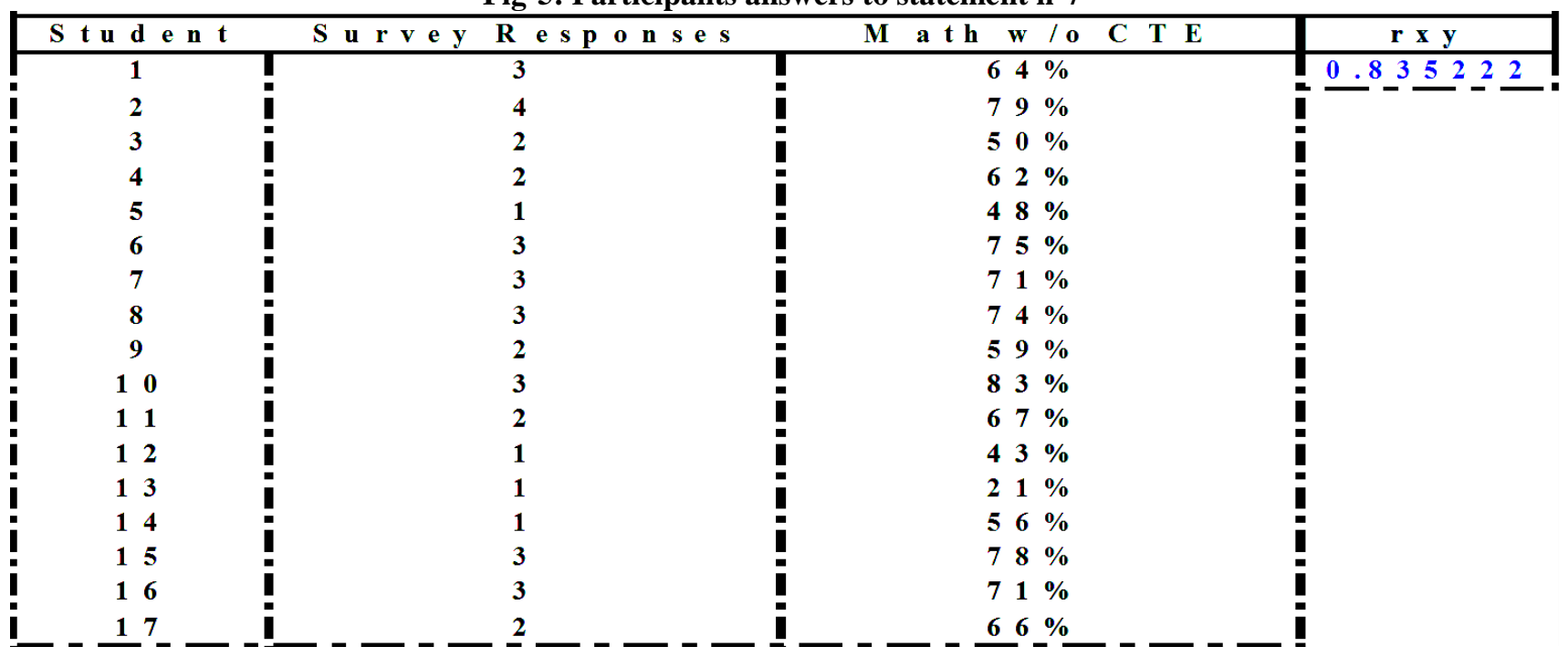

Such a result illustrates clearly the correlation of student confidence in mathematics (Algebra) and Pretest \#1 math scores. As can be seen, the correlation coefficient (rxy) equates to 0.84 . Therefore, the line of best fit shows a positive correlation between student's (lack) of confidence and Pretest \#1 math scores. 


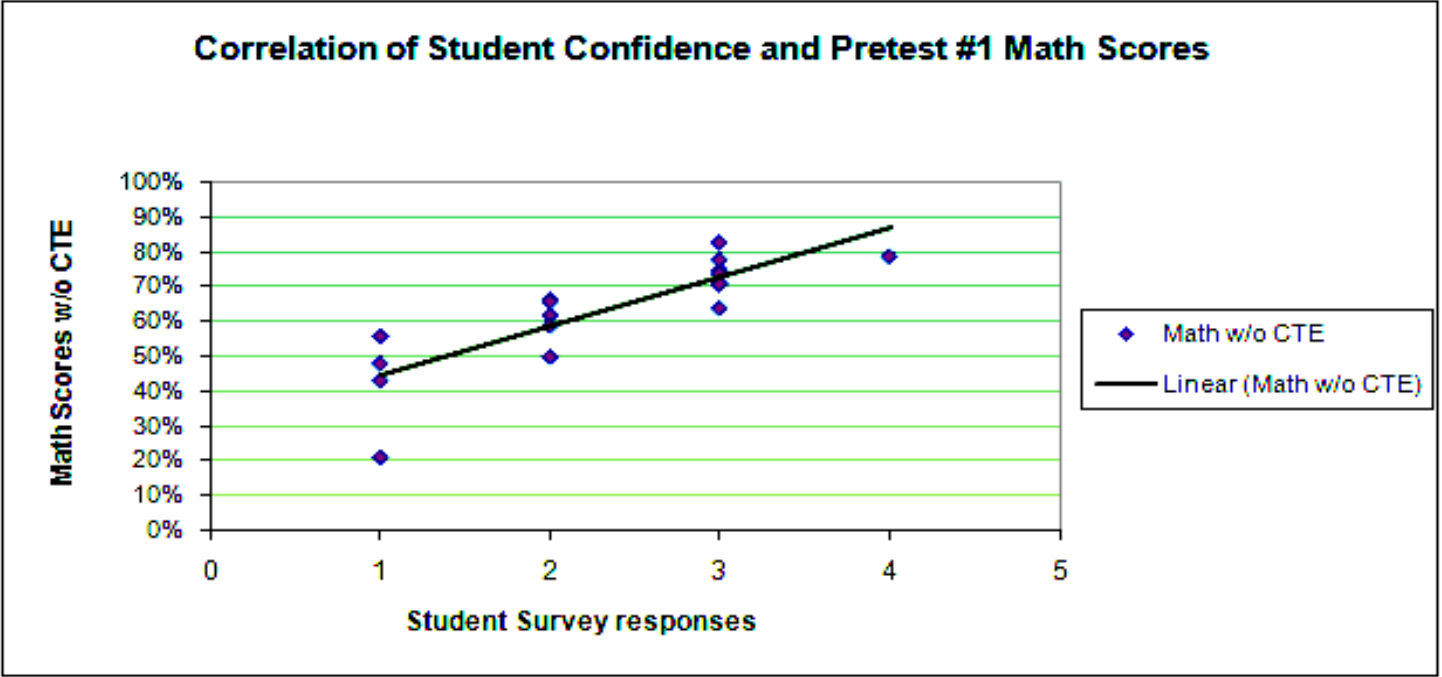

\section{Pretest Correlation $\mathbf{n}^{\circ} 2$}

The datum collected and presented below is an extract from the Student survey. It concerns specifically statement $\mathrm{n}^{\circ} 7$ which goes as follows:

\section{Statement 7: Solving math problems often makes me nervous and upset.}

Strongly Agree

(1)
(2)
(3)

\section{Strongly Disagree}

(4)

The results from students are presented in the figure below:

Figure -: Participants answers to statement $n^{\circ} 7$

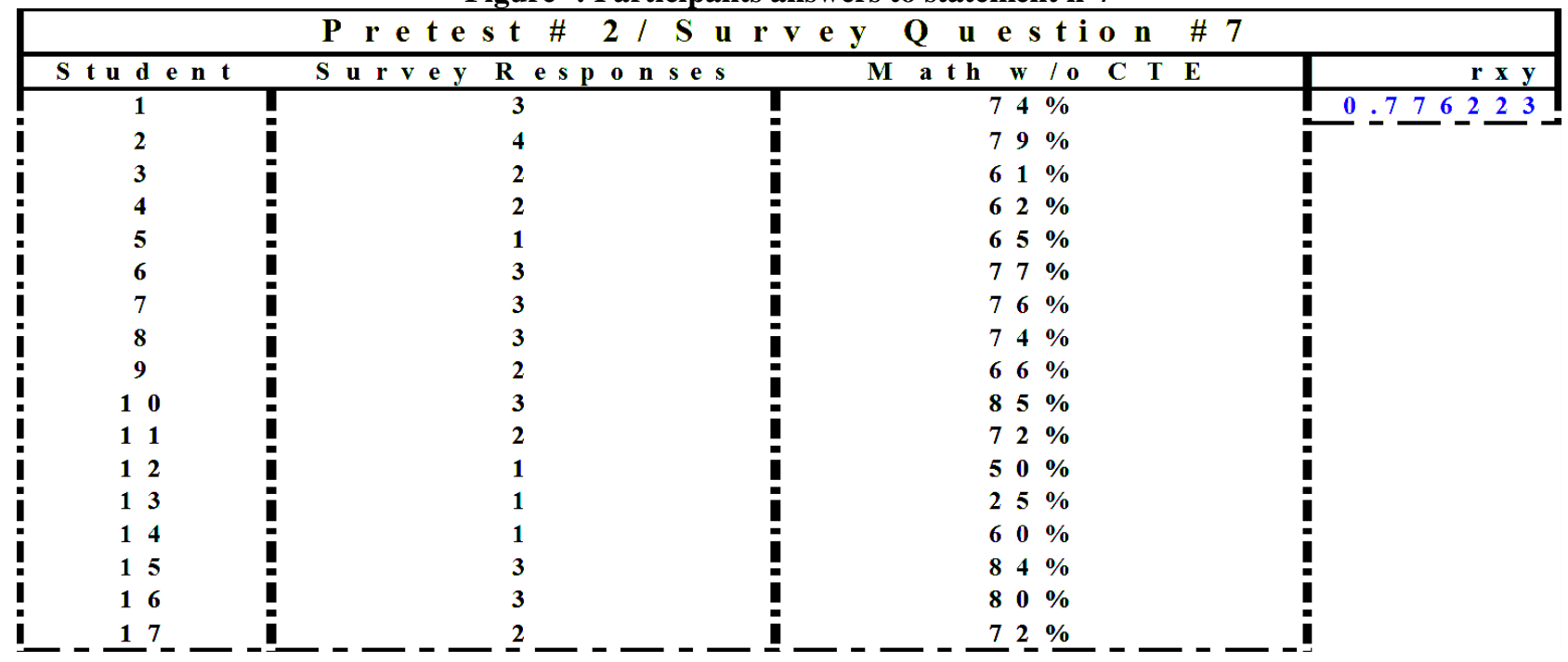

Such a result demonstrates the correlation of content mastery in mathematics and Posttest \#2 math scores. As can be seen, the correlation coefficient (rxy) equates to $=0.78$. Therefore, the line of best fit shows the line of best fit shows a fair, positive correlation between student's (lack) of confidence and Pretest \#2 math scores. 


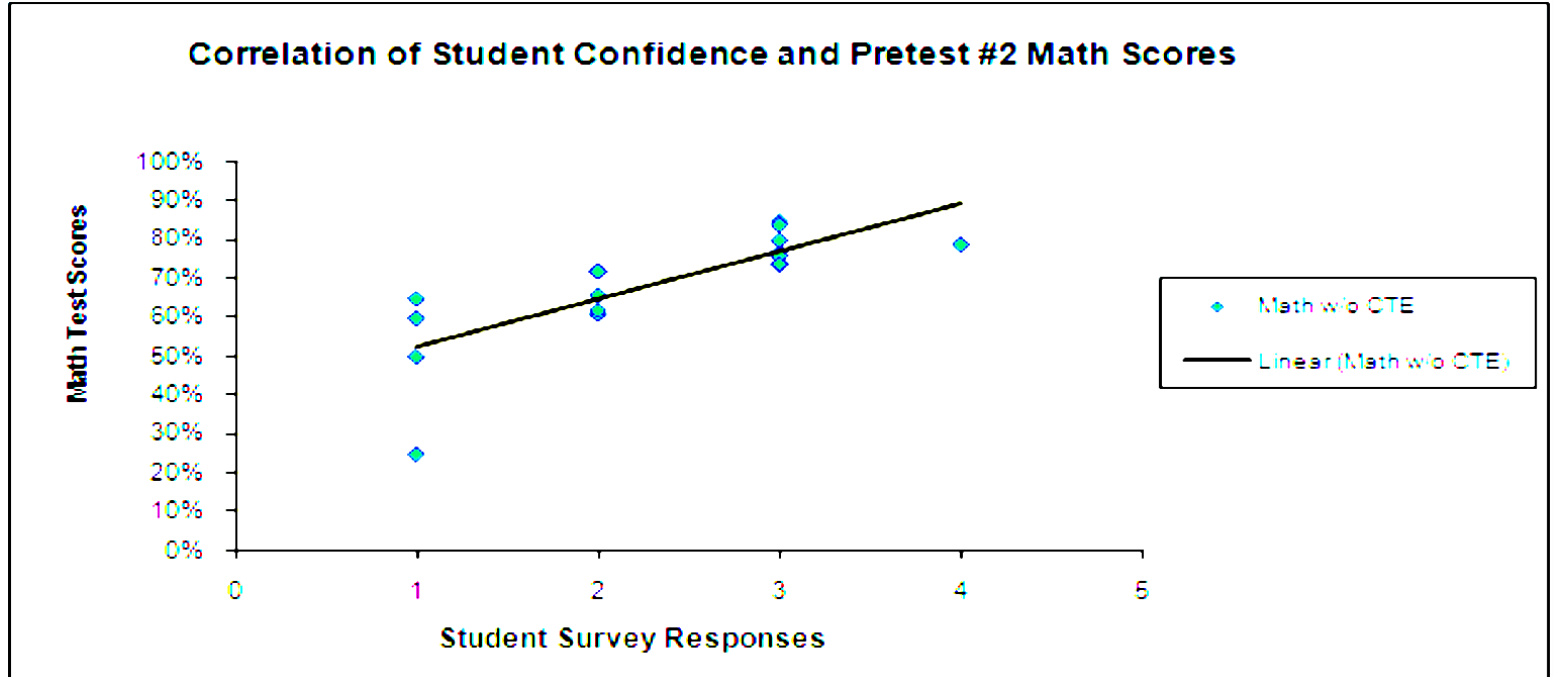

\section{Posttest Correlation $n^{\circ} 1$}

The datum collected and presented below is an extract from the Student survey. It concerns specifically statement $n^{\circ} 8$ which goes as follows:

Statement 8: I enjoy math more when blended with the CTE/Masonry Co-teacher because he makes solving math problems more understandable.

Strongly Agree

(1)
Agree

(2)
Disagree

(3)

\section{Strongly Disagree}

(4)

The results from students are presented in the figure below:

Figure: Participants answers to statement $n^{\circ} 8$

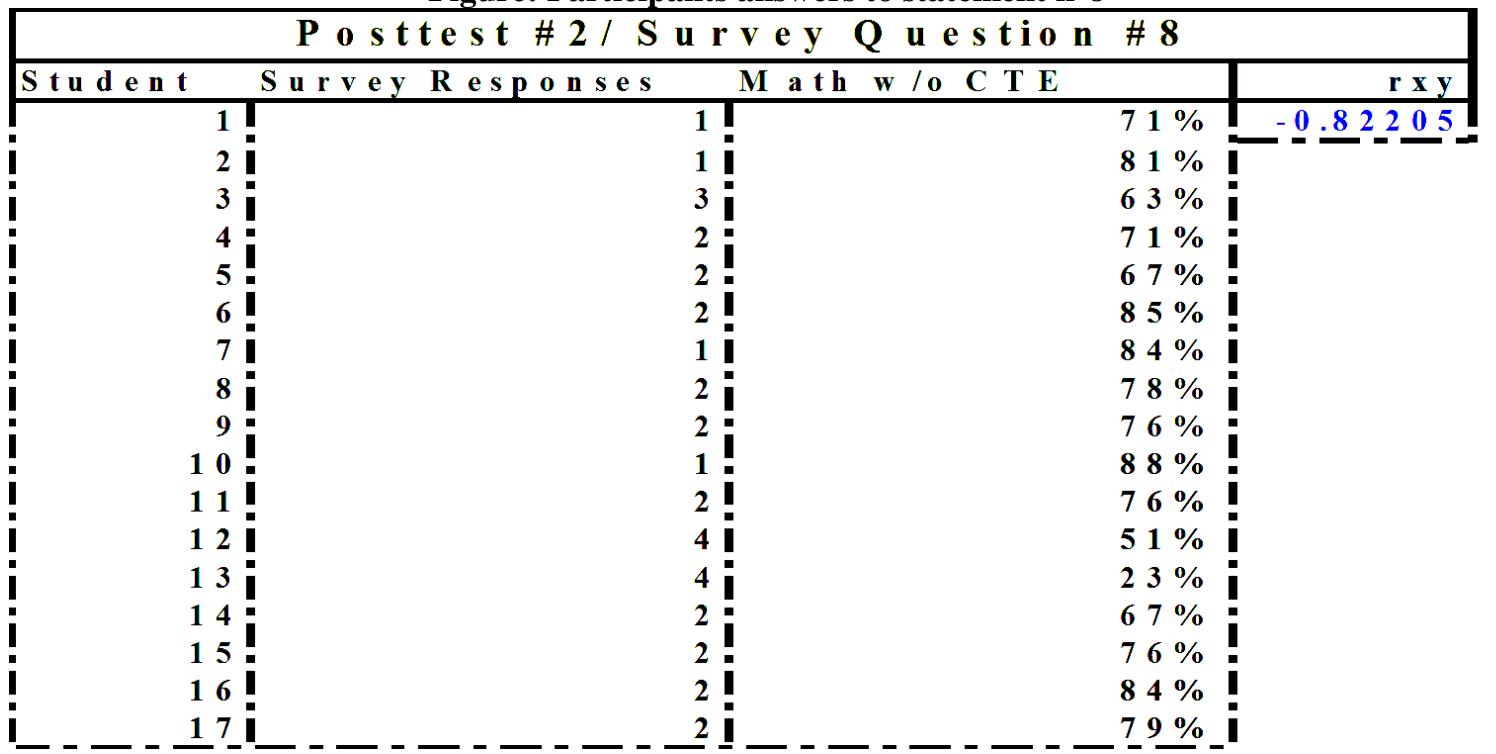

As evident, the correlation coefficient (rxy) equates to 0.82 . Therefore, the line of best fit shows a fair, negative correlation between student's content mastery and Posttest \#2 math scores. 


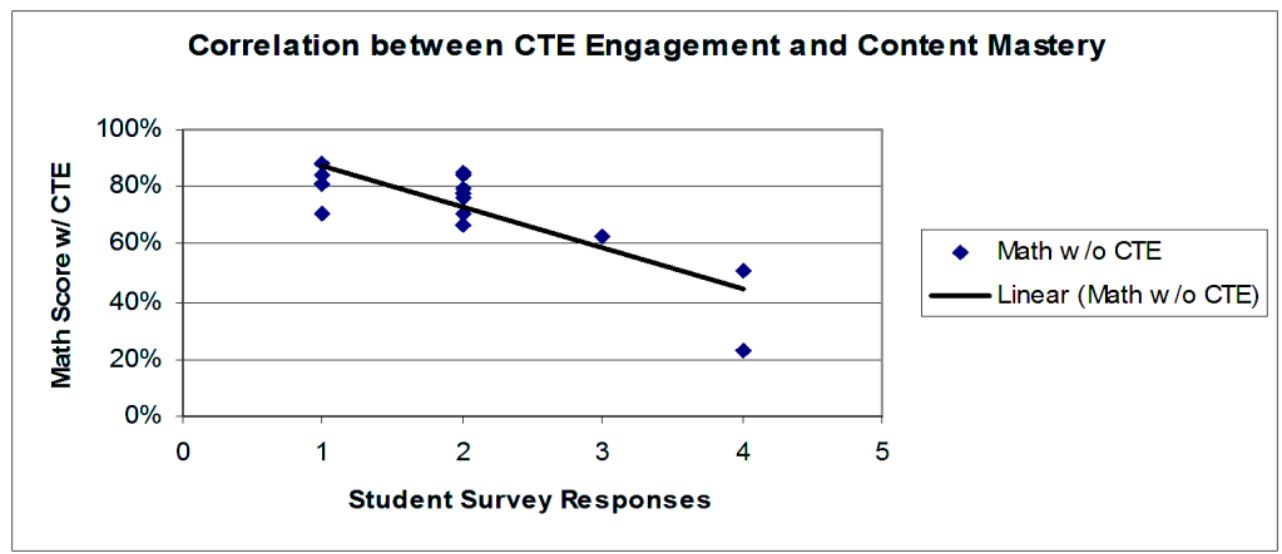

\section{Posttest Correlation $\mathbf{n}^{\circ} 2$}

The datum collected and presented below is an extract from the Student survey. It concerns specifically statement $\mathrm{n}^{\circ} 8$ which goes as follows:

Statement 8: I enjoy math more when blended with the CTE/Masonry Co-teacher because he makes solving math problems more understandable.
Strongly Agree
(1)
Agree
Disagree
(3)
Strongly Disagree
(2)
(4)

The results from students are presented in the figure below:

Figure: Participants answers to statement $n^{\circ} 8$

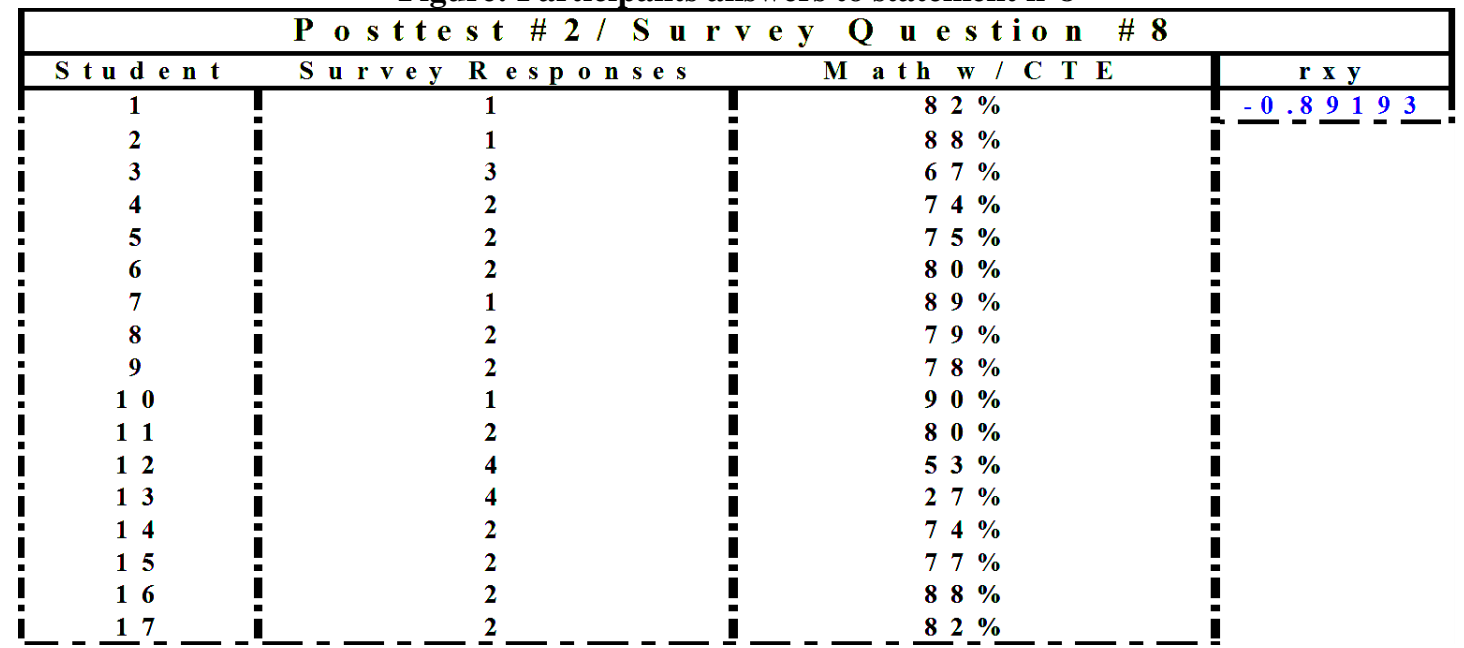

As is observable, the correlation coefficient (rxy) equates to 0.89 . Therefore, the line of best fit shows a negative correlation between student's content mastery and Posttest \#2 math scores.

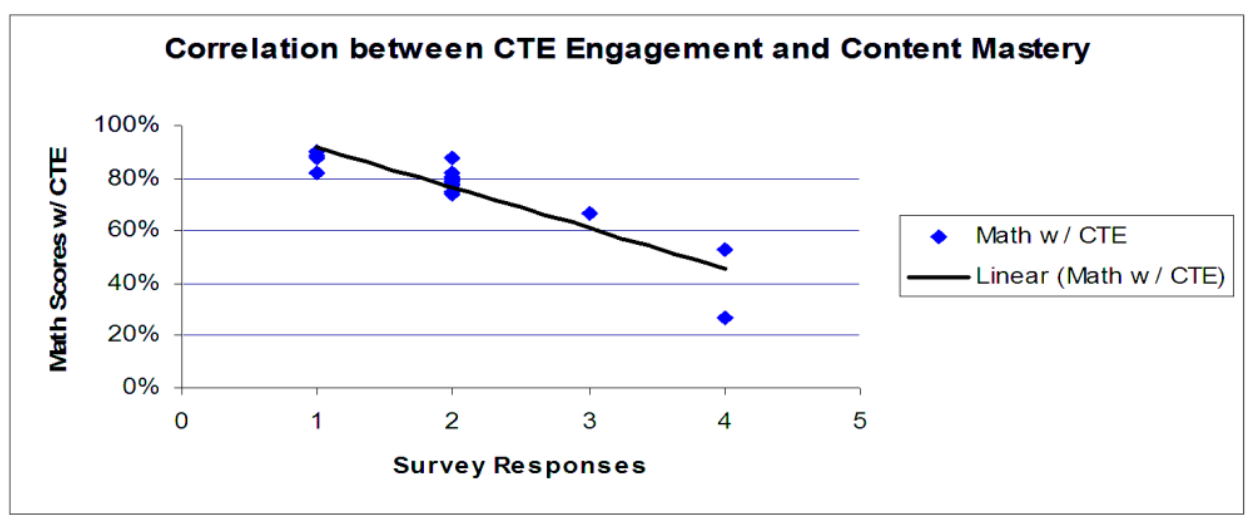


To summarize the results of the PreExperimental Design, it is to be noted that 34 students were pretested (O), exposed to CTE-Maths (Algebra) treatment $(\mathrm{X})$, and posttested $(\mathrm{O})$. The values obtained are $75 \%$ Mean, $79 \%$ Median and Mode is $82 \%$. Such results show that $71 \%$ of the student test scores (as indicated in Posttest \#2) improved over the course of 5 months. Ten of the thirty-four student math scores or 29 $\%$ is approximately 1 standard deviation below the mean. The Standard Deviation from the Mean was +/.15

\section{DISCUSSION}

The purpose of the research was to explore the effectiveness of CFPs as an alternative to re-engage the disaffected students in education. The main hypothesis supported was that CTE programs as implemented in CFPs are effective to connect academic understanding to the relevance of abstract content areas like mathematics.

The results of the data collected showed that $94 \%$ of the student's math scores increased over a period of five months (January to May 2018). The student participants will sit for the Maths (Algebra) test as part of their end of training and qualification exam called Certificat de Qualification Professionnelle in June or July. Basing on these results, it is possible to predict that $82 \%$ of them will pass this test. Moreover, the results have also demonstrated that alternative educational methods employed through CTE at CFP Dogbo successfully address the needs of not only the atrisk students but others too. This is apparent through the Centre giving opportunity to their in-service teachers to co-plan and implement individualized instructional goals for individual student that leads towards graduation with a diploma and learning beyond the classroom. Furthermore, the instructional methods implement the Experiential and Contextualized approach to learning. Therefore, it can be stated beyond doubt that both Contextualized and Experiential Learning use positive methods that help at-risk youth (who already know failure) make all necessary breakthroughs away from memories of past failures. Hence, when teachers constructively instill the Contextualized and Experiential approach, they foster a "real" relationship with the at-risk students that can achieve positive results.

\section{CONCLUSION}

From the thorough analyses of the data collected, it emerges that the CFPs mission of educating at-risk students positively influence the engagement of abstract subjects like mathematics (algebra) when the content of the curriculum is practical and more relevant to the student's life [11]. However, further studies involving more detailed aims, longer duration as well as larger groups are needed to truly investigate the issue.

\section{REFERENCES}

1. Alfeld, C., Hansen, D., Aragon, S., \& Stone, J. (2006). Inside the black box: Exploring the value added by career and technical student organizations to students' high school experience. Career and Technical Education Research, 31(3):121-55. Retrieved September 23, 2009, from Eric Education Full Text database.

2. Jodelet, D., \& Lage, É. (2002). Psychologie sociale. Annuaire de l'EHESS. Comptes rendus des cours et conférences, 673-675.

3. Aron, L. Y. (2006, January). An overview of alternative education. The Urban Institute. Retrieved September 17, 2009, from http://www.urban.org/UploadedPDF/411283_alter native_education.pdf

4. D'Angelo, F., \& Zemanick, R. (2009). The twilight academy: An alternative education program that works. Preventing School Failure, 53(4), 211-18. Retrieved September 23, 2009, from Eric Education Full Text database.

5. Bennett, J. (2007). Work-based learning and social Support: Relative influences on high school seniors' occupational engagement orientations. Career and Technical Education Research, 32(3), 187-214. Retrieved September 23, 2009, from Eric Education Full Text database.

6. Zweig, J. (2003, June). Vulnerable youth: Identifying their needs for alternative educational settings. The Urban Institute. Retrieved November 17, 2009, from http://urbaninstitute.org/UploadedPDF/410828_vu lnerable_youth.pdf

7. Gunn, T., Chorney, D., \& Poulsen, J. (2009). High school completion: A comprehensive review of projects directed toward keeping students in school. Journal of At-Risk Issues, 15(1):17-24. Retrieved November 17, 2009, from Eric Education Full Text database.

8. Foley, R., \& Pang, L. (2006). Alternative education programs: Program and student characteristics. The High School Journal, 89(3):10-21. Retrieved September 23, 2009, from Eric Education Full Text database.

9. Hughes-Hassell, S. (2008). Alternative educational settings: What can we learn from them? Knowledge Quest, 37(1), 8-11. Retrieved September 23, 2009, from Eric Education Full Text database.

10. Due to useless spacing issues, results are compiled by pairs in this table and subsequent ones.

11. Rogers, C. R. (1969). Freedom to learn. Columbus, $\mathrm{OH}$ : Merrill. 